\title{
Gold Standard Care of Chronic Scrotal Pain
}

\author{
Stefan Artell Malaguti ${ }^{1}$ \\ Lars Lund ${ }^{1,2}$ \\ 'Department of Urology, Odense \\ University Hospital, Odense, Denmark; \\ ${ }^{2}$ Department of Clinical Research, \\ University of Southern Denmark, \\ Odense, Denmark
}

Introduction: Chronic scrotal pain (CSP) can be a debilitating condition for patients and is often difficult to characterize.

Methods: A review of literature was performed using Embase, Cochrane and Medline databases in the period 1.January 2010 to 1 .January 2021. We found 132 articles, and the authors screened abstract and references. Thirty-seven articles are included after removing duplicates.

Results: This review presents a variety of medical and surgical treatment options for CSP such as spermatic cord blocks (36-80\% success rate), microsurgical denervation of the spermatic cord (76-100\% success rates), Botox (56\% success rate), targeted ilioinguinal and iliohypogastric peripheral nerve stimulation, and radical orchiectomy (55-75\% success rate).

Conclusion: An overview of various treatment options, both non-surgical and surgical are provided, with the aim of establishing what may be the best treatment option for CSP.

Keywords: scrotum, chronic, pain, testis

\section{Introduction}

Scrotal pain is an umbrella term referring to a variety of problems causing discomfort or pain in the scrotum and may be caused by problems with the testis or other contents of the scrotum, including ductus deferens and epididymis.

Chronic scrotal pain (CSP) is defined as constant or intermittent pain in the scrotum lasting for more than three months. ${ }^{1}$ CSP does not involve only testicular pain, as there may be pain involving the epididymis, vas deferens or adjacent paratesticular structures.

It is important that, on first presentation, any scrotal pain, regardless of pain severity, is assessed and managed on the principles of an acute scrotum, due to time-sensitive conditions such as testicular torsion. ${ }^{1}$

The patient with acute scrotal pain is the urologist's acute abdomen. Therefore, a thorough medical history and objective examination in order to make a tentative diagnosis (age, sexual medical history and duration, severity, description of pain) is essential. Para clinical examinations are sometimes necessary to support a clinical diagnosis. The balance is between the potential risk of exploring or have a conservative treatment. The typical acute are reviewed in the following: torsio testes or torsio appendicis, epididymitis or other infection (epididymo-orchitis, Fournier's gangrene, inflammation (dermatitis, vasculitis, cellulitis), ischemia (incarcerated hernia), trauma, medication (Amiodarone) or be referred pain (appendicitis, aneurysm, ureteral stones) Some recognized causes of scrotal pain include spermatocele and varicocele, hydrocele, infected hycrocele and testis tumor. ${ }^{1}$
Correspondence: Lars Lund University Hospital, J.B.Winsløwsvej 4,

Odense, 5000, Denmark

Email Lars.Lund@rsyd.dk 
Another pathophysiological cause of CSP revolves around wallerian degeneration in spermatic cord nerve fibers. This is evidenced by a paper published in 2013 that found that out of 56 men treated for CSP, 48 of them $(84 \%)$ showed wallerian degeneration in 1 or more spermatic cord nerve fibers, whilst in the controls only $20 \%$ showed this degeneration. ${ }^{2}$

The nerve supply takes place mainly through the ilioinguinal nerve and the genitofemoral nerve, which can be helpful in diagnosing the disease in question, especially in cases with CSP. An overall treatment strategy for evaluation of scrotal pain is shown in Figure 1.

CSP is not the same as scrotal pathology. It can be very frustrating for the patient to live with and challenging for clinicians to treat. In about $25-50 \%$ of patients, the pathophysiological cause is unknown and may be associated with depression, anxiety or previous abuse. Conditions significantly affect the quality of life, e.g. sexuality, work possibilities, social relationships and mental health.

In patients with CSP it is often essential to repeat a thorough history, objective examination, urine analysis and ultrasound scan of the scrotum trying to determine the exact etiology, if possible.

Therefore, CSP can be a debilitating condition for patients. Due to the lack of clearly defined treatment guidelines, one may also experience a certain difficulty in treating this condition.

However, CSP is often idiopathic and may be associated with vasectomy procedures. A systematic review showed that the overall average incidence of CSP due to vasectomy was $15 \%$, with $24 \%$ in scalpel vasectomy and $7 \%$ in non-scalpel vasectomy. ${ }^{3}$

Other, rarer causes include hernia repair and thoracolumbar junction syndrome. ${ }^{4,5}$ CSP may, possibly, be a misdiagnosis in for example those with chronic hip pain. ${ }^{6}$

The aim is to describe possible treatment options, both surgical and non-surgical, and to specify a "gold standard" treatment.

\section{Assessment of CSP}

In 2018, a new assessment tool was developed to help classify symptoms in those with CSP. This tool known as

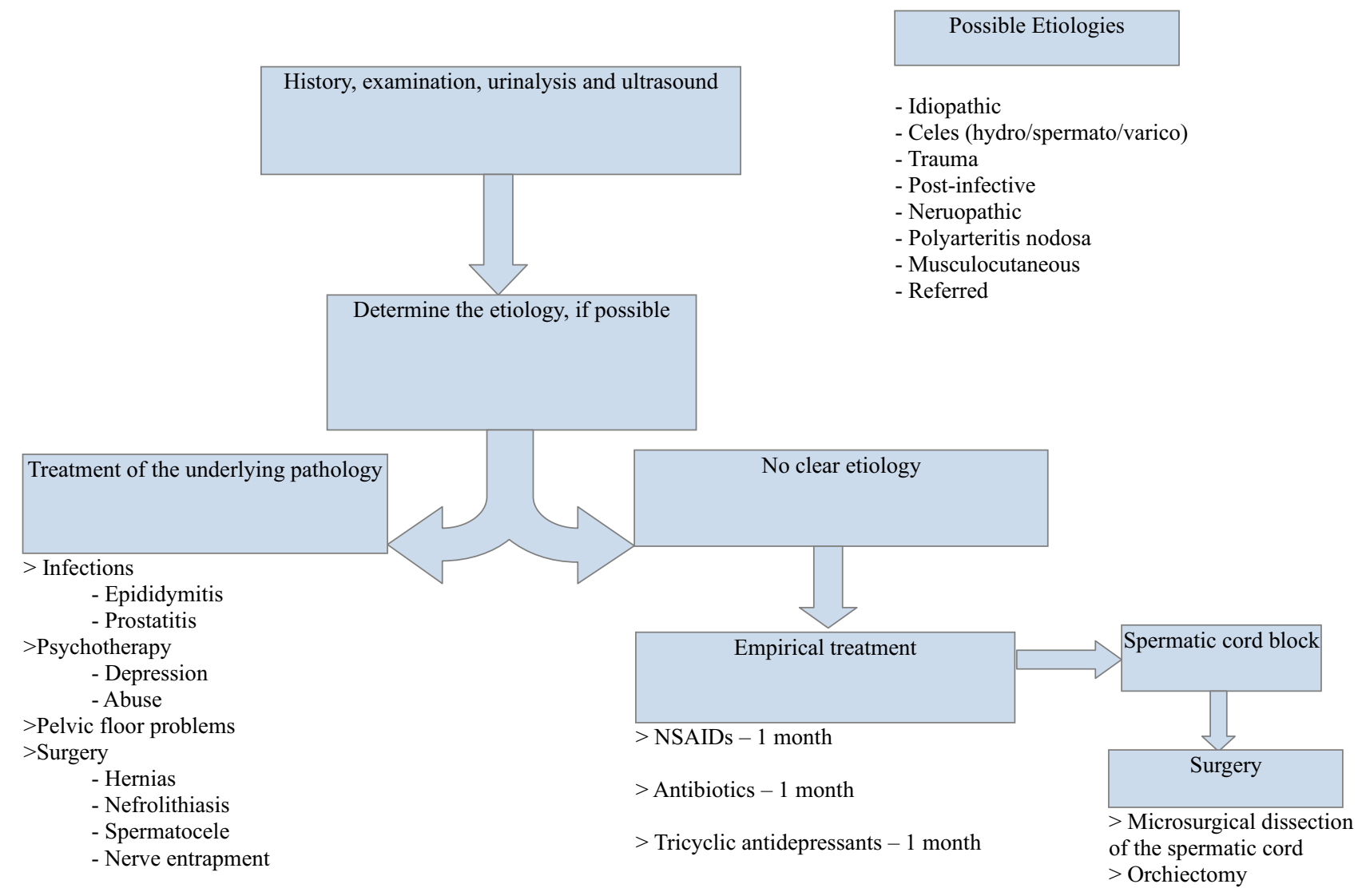

Figure I A flowchart of a way to tackle chronic scrotal pain (CSP) with a systematic approach. 
chronic symptom index score (COSI) uses 12 questions in 3 different domains (pain, sexual symptoms, quality of life). ${ }^{7}$ Furthermore, a paper published later in the same year had the aim of validating the COSI. This was done by giving the tool to 170 men with CSP, and assessing their scores based on a variety of factors including internal reliability, internal consistence, responsiveness and linear progression. Their conclusion was that COSI is a valid and clinically relevant symptom index to assess severity of CSP and response to therapy. ${ }^{8}$

\section{Non-Surgical Treatment Options}

A variety of non-surgical treatment options exist for CSP. These can be trialed alone or as a combination with other non-surgical or surgical options, and are often initiated as first-line treatment.

\section{Physical Therapy}

Up to $10 \%$ of patients, who present with CSP, are found to have musculoskeletal pain localized to areas that may include the conjoint tendon, the adductor tendon and the pelvic floor. ${ }^{9}$ Because of this, patients may benefit from physical therapy such as perineal/pelvic-floor exercises. Due to the relative ease of this method, together with its absence of side effects, this should be a first-line option, ideally in conjunction with other non-surgical options as described below.

\section{Medications}

Non-steroidal anti-inflammatory drugs (NSAIDs) such as Ibuprofen, tricyclic antidepressants (TCAs) e.g. nortriptyline and anticonvulsants e.g. gabapentin have proven successful in the management of CSP. For example, $61.5 \%$ of patients commenced on gabapentin and $66.6 \%$ of patients commenced on nortriptyline had a greater than $50 \%$ improvement in pain. ${ }^{10}$

However, it is not as effective when considering only CSP caused by vasectomies due to this subgroup all having less than $50 \%$ improvement in their pain. ${ }^{10}$

\section{Psychotherapy}

CSP can have a significant impact on the life of a patient. The constant pain can affect their sexual drive, their social habits and may exhibit symptoms of depression. If significant psychological distress is present, it can be advised to refer patients to a mental health specialist.

Beyond this, psychotherapy such as cognitive behavioral therapy (CBT) has shown benefits in other chronic pain syndromes and should be considered a possible tool in the fight against $\mathrm{CSP}^{11}$

\section{Muscle Relaxants}

A cohort study of 499 patients discusses the comparative efficacy of terazosin (alpha-blocker) and baclofen (skeletal muscle relaxant) in young men with chronic orchialgia. ${ }^{12}$

The results show, that both of these drugs have a possible role in the treatment of CSP, due to them both having causing a reduction in National Institutes of Health Chronic Prostatitis Symptom Index scores over a period of three months. Interestingly, there seemed to be no difference between the two medications. ${ }^{12}$

\section{Spermatic Cord Block Series}

While a spermatic cord block, involving injecting local anesthesia such as bupivacaine without adrenaline into the spermatic cord at the level of the pubic tubercle, is known to alleviate CSP, but this is not a permanent treatment option. ${ }^{13}$

A study investigated a spermatic cord block series with repeated injections of local anesthetic (bupivacaine) together with triamcinolone acetonide, a corticosteroid, into the spermatic cord. ${ }^{13}$ In this retrospective study, an average of 3.6 blocks were used. At the completion of this series, $36.2 \%$ reported a complete resolution of symptoms while $44.7 \%$ reported a partial resolution of symptoms. ${ }^{13}$ Interestingly, a modified block using Marcaine local anesthetic was found to be a good tool as an effective predictor of success following microscopic spermatic cord denervation (see below). ${ }^{14}$

\section{Botulinum Toxin}

A few studies have attempted the use of onabotulinum toxin A as a treatment for CSP with an injection of the toxin as a spermatic cord block.

A randomized, double-blind, controlled trial showed that there was no superiority of giving local anesthesia with onabotulinum toxin A over local anesthesia alone. ${ }^{15}$ Interestingly, however, a pilot open-label trial showed that the injection of onabotulinum toxin A alone provided both pain and tenderness reduction in a period over 3 months in $56 \%$ of patients. It is possible that the toxin could be used as an alternative, or that the injection itself had a placebo effect. ${ }^{15,16}$

\section{Surgical Treatment Options}

There exist a variety of different surgical treatment options for CSP. Each have varying efficacy and possible risks 
involved. They are generally kept as second or even thirdline option for persistent cases.

\section{Microsurgical Denervation of the Spermatic Cord}

Microsurgical denervation of the spermatic cord (MDSC) is perhaps one of the most well-studied surgical treatments for CSP. MDSC is performed using an inguinal incision at the level of the external inguinal ring and uses an operating microscope to divide the nerve fibers of the ilioinguinal nerve. ${ }^{17}$

As previously mentioned, a paper has been published regarding the wallerian degeneration in spermatic cord nerve fibers. This could explain why MDSC, which involved transection of these nerve fibers, provides relief in well over half of those who undergo this procedure. ${ }^{2}$

Two separate studies published in 2001 and 2018 show that MDSC is a viable surgical option. In the first study including 33 patients, complete pain relief was noted in 25 patients (76\%) and partial relief in 3 patients $(9.1 \%)$. In the second study including 17 patients with CSP as a complication of vasectomy, 13 patients $(76.5 \%)$ reported complete pain relief on their follow-up visits. ${ }^{18,19}$

A case series describes how robotic MDSC is also a possibility, with all three $(100 \%)$ patients experiencing postoperative resolution of their $\mathrm{CSP}^{20}$ This is further confirmed by a large series review by Nahomy Calixte et al. from 2018, where a follow up of 860 cases whom had undergone robot-assisted MDSC showed that 718 $(83 \%)$ of patients had a significant reduction in pain. Of these, $426(49 \%)$ had a complete resolution of pain and $292(34 \%)$ had a reduction of $50 \%$ or greater. ${ }^{21}$ This is relevant as it offers more urologists the ability to use their familiar techniques to treat CSP.

Interestingly, a study published in 2020 showed that when comparing monopolar electrocautery, which is the standard ligation energy source in robotic MDSC, to flexible fiber-optic carbon dioxide laser probe, the latter resulted in significantly less collateral thermal injury when compared to the former. ${ }^{22}$

A few studies have also looked into whether or not spermatic cord blocks can predict the success following MDSC. This was investigated in a retrospective review of 74 patients who underwent MDSC between 2006 and 2010. They found that the level of temporary improvement from the cord block did indeed appear to be a useful predictor of sustained improvement with MDSC. ${ }^{23}$

\section{Peripheral Nerve Stimulation}

In 2013, Frederikke Rosendal et al. published a case report where peripheral nerve stimulation was used to successfully treat a case of resistant $\mathrm{CSP}^{24}$ By implanting two percutaneous leads in his groin to provide low-frequency stimulation of the cutaneous branch of the ilioinguinal and genital branch of the genitofemoral nerve, a 30 year old man with a four-year history of chronic testicular pain following scrotal hydrocele surgery experienced dramatic improvement, with a vas score on the numeric rating scale for pain declining from $9 / 10$ to $2 / 10$. Therefore, it may be attractive to consider this as an option for some cases of $\mathrm{CSP}^{24}$

\section{Spinal Cord Stimulation}

Much in similar line with peripheral nerve stimulation, spinal cord stimulation may explored as a treatment option for CSP. A case study by Kent H Nouri (2011) describes the implantation of spinal cord stimulator electrodes in a 57 year old gentleman with malignancy related CSP. This stimulation resulted in a sustained $80 \%$ decrease of pain at 6 weeks status post-permanent implantation of the electrodes, with self-reported increase of function at work and complete weaning off oral analgesics. ${ }^{25}$

\section{Cryo-Ablation}

In patients who failed MDSC, one could offer salvage cryo-ablation. It is performed ultrasound guided with targeted cryo-ablation of the peri-spermatic cord tissue. The study included 279 patients, who underwent salvage cryoablation of genitofemoral, ilioinguinal, and inferior hypogastric nerves medial and lateral to spermatic cord at external inguinal ring level. Seventy-five percent reduction in pain with VAS. Fifty-three percent reduction in pain 1 month, increased to $64 \%$ by 5 -year follow-up. ${ }^{26}$

\section{Hydrodissection}

Ahmet Gudeloglu et al published an article regarding the use of hydrodissection for improved MDSC, a prospective blinded randomized control trial in a rat model. This showed that the use of hydrodissection significantly decreases residual nerve density without compromising vascular integrity in a rat model. ${ }^{27}$

While there does not seem to a true "golden standard" treatment for CSP, one may argue that hydrodissection could be an interesting method with future potential. 


\section{Orchiectomy}

As a last resort for cases of CSP that are resistant to virtually all other treatment options, one may consider an orchiectomy. This, unfortunately, does not guarantee successful pain cure.

A review shows that orchiectomy is more effective as a treatment option when done via an inguinal approach, with approximately $75 \%$ of patients experiencing resolution of symptoms. In contrast, only around 55\% experienced resolution of symptoms when the operation was done via a scrotal approach. ${ }^{28}$

\section{Future Direction}

The constantly evolving literature of CSP has led to the increased knowledge of diagnosis and treatment, from oral medications to invasive treatments. This is shown by an extensive review published earlier this year. ${ }^{29}$ With each study, we develop a more thorough, evidence-based algorithm to guide urologists in treatment of CSP.

\section{Conclusion}

In general, CSP is a poorly understood problem with a variety of causes and considerations, which still requires more research in the future.

There are useful non-surgical and surgical options for CSP that depend on the patient's state, the severity of the complaint and what options have already been tried.

We recommend for the individual patient when other etiologies are ruled out to use multidisciplinary treatment modalities including physical therapy and psychotherapy as useful tools for coping with this condition.

\section{Disclosure}

The authors report no conflicts of interest in this work.

\section{References}

1. Levine L. Chronic orchialgia: evaluation and discussion of treatment options. Ther Adv Urol. 2010;2(5-6):209-214. doi:10.1177/ 1756287210390409

2. Parekattil SJ, Gudeloglu A, Brahmbhatt JV, Priola KB, Vieweg J, Allan RW. Trifecta nerve complex: potential anatomical basis for microsurgical denervation of the spermatic cord for chronic orchialgia. $J$ Urol. 2013;190(1):265-270. doi:10.1016/j. juro.2013.01.045

3. Auyeung AB, Almejally A, Alsaggar F, Doyle F. Incidence of post-vasectomy pain: systematic review and meta-analysis. Int J Environ Res Public Health. 2020;17(5):1788. doi:10.3390/ ijerph 17051788

4. Aoun F, Malek E, Kazan D, et al. Management of chronic testicular pain due to thoracolumbar junction syndrome: a Pilot Study. Prog Urol. 2020;30(2):114-118. doi:10.1016/j.purol.2019.12.002
5. Aljumaily A, Al-Khazraji H, Gordon A, Lau S, Jarvi KA. Characteristics and etiologies of chronic scrotal pain: a common but poorly understood condition. Pain Res Manag. 2017;2017:3829168. doi: $10.1155 / 2017 / 3829168$

6. Chouhan JD, Scarberry K, Thakker PU, Vanhorn T, Terlecki RP. Hip joint pathology among men referred to urology for chronic orchialgia: a source for misdiagnosis and opportunity for quality improvement. Urology. 2020;146:96-100. doi:10.1016/j. urology.2020.06.089

7. Polackwich AS, Arora HC, Li J, et al. Development of a clinically relevant symptom index to assess patients with chronic orchialgia/ chronic scrotal contents pain. Transl Androl Urol. 2018;7(Suppl 2): S163-S168. doi:10.21037/tau.2018.04.10

8. Shoskes DA, Calixte N, Tadros N, Li J, Parekattil S. Validation of the chronic orchialgia symptom index for men with chronic orchialgia/ chronic scrotal contents pain. Urology. 2018;119:39-43. doi:10.1016/ j.urology.2018.05.030

9. Moubasher A, Waqar M, Raison N, Brunckhorst O, Ahmed KA Review of the management of chronic scrotal pain. Cureus. 2020;12(12):e11979.

10. Sinclair AM, Miller B, Lee LK. Chronic orchialgia: consider gabapentin or nortriptyline before considering surgery. Int J Urol. 2007;14 (7):622-625. doi:10.1111/j.1442-2042.2007.01745.x

11. Wu C, Jarvi K. Management of chronic scrotal content pain. Can Urol Assoc J. 2018;12(6 Suppl 3):S164-S166. doi:10.5489/cuaj.5326

12. Mohseni-Rad H, Razzaghdoust A, Mishan MA, Gholamrezaie HR, Hosseinkhani A. Terazosin or baclofen in young men with chronic orchialgia: a cohort study of 499 patients. Urologia. 2020;87 (1):35-40. doi:10.1177/0391560319873531

13. Beamer M, Nickel JC, Kravchick S. MP58-11 A modified preoperative spermatic cord block predicts success following microscopic spermatic cord denervation surgery for chronic scrotal pain. J Urol. 2020;203:e875-e875. doi:10.1097/JU.0000000000000927.011

14. Simon D, Bajic P, Lynch K, Levine L. MP58-10, spermatic cord block series as a treatment for chronic scrotal content pain. $J$ Urol. 2020;203:e874-e875. doi:10.1097/JU.0000000000000927.010

15. Khambati A, Lau S, Gordon A, Jarvi KA. OnabotulinumtoxinA (Botox) nerve blocks provide durable pain relief for men with chronic scrotal pain: a pilot open-label trial. J Sex Med. 2014;11 (12):3072-3077. doi:10.1111/jsm.12707

16. Dockray J, Aljumaily A, Lau S, Jarvi KA, Randomized A. Doubleblind, controlled trial shows that onabotulinum toxin A nerve blocks do not provide improved pain control in men with chronic scrotal pain. J Urol. 2020;203(4):767-772. doi:10.1097/ JU.0000000000000658

17. Levine LA. Surgical techniques: microsurgical denervation of the spermatic cord. J Sex Med. 2008;5(3):526-529. doi:10.1111/j.17436109.2007.00762.x

18. Levine LA, Matkov TG. Microsurgical denervation of the spermatic cord as primary surgical treatment of chronic orchialgia. J Urol. 2001;165(6 Pt 1):1927-1929. doi:10.1016/S0022-5347(05)66244-1

19. Tan WP, Levine LA. Micro-denervation of the spermatic cord for post-vasectomy pain management. Sex Med Rev. 2018;6(2):328-334. doi:10.1016/j.sxmr.2017.06.002

20. Goedde MA, Nguyen KD, Choi KB. Robotic microsurgical spermatic cord denervation for chronic orchialgia: a case series. $J \mathrm{Am}$ Osteopath Assoc. 2021;121(1):29-34.

21. Calixte N, Tojuola B, Kartal I, et al. Targeted robotic assisted microsurgical denervation of the spermatic cord for the treatment of chronic orchialgia or groin pain: a single center, large series review. J Urol. 2018;1994(4):1015-2022. doi:10.1016/j.juro.2017.10.030

22. Gudeloglu A, Kattoor AJ, Brahmbhatt J, Parekattil S, Agarwal A. Prospective control trial: flexible CO2 laser vs. monopolar electrocautery for robotic microsurgical denervation of the spermatic cord. Int J Impot Res. 2020;32(6):623-627. doi:10.1038/s41443-02000352-0 
23. Benson JS, Abern MR, Larsen S, Levine LA. Does a positive response to spermatic cord block predict response to microdenervation of the spermatic cord for chronic scrotal content pain? J Sex Med. 2013;10(3):876-882. doi:10.1111/j.1743-6109.2012.02937.x

24. Rosendal F, Moir L, de Pennington N, Green AL, Aziz TZ. Successful treatment of testicular pain with peripheral nerve stimulation of the cutaneous branch of the ilioinguinal and genital branch of the genitofemoral nerves. Neuromodulation. 2013;16(2):121-124. doi:10.1111/j.1525-1403.2011.00421.x

25. Nouri KH, Brish EL. Spinal cord stimulation for testicular pain. Pain Med. 2011;12(9):1435-1438. doi:10.1111/j.1526-4637.2011.01210.x

26. Calixte N, Kartal IG, Tojuola B, et al. Salvage ultrasound-guided targeted cryoablation of the perispermatic cord for persistent chronic scrotal content pain after microsurgical denervation of the spermatic cord. Urology. 2019;130:181-185. doi:10.1016/j.urology.2019.04.027
27. Gudeloglu A, Brahmbhatt JV, Allan R, Parekattil SJ. Hydrodissection for improved microsurgical denervation of the spermatic cord: prospective blinded randomized control trial in a rat model. Int $J$ Impot Res. 2021;33(1):118-121. doi:10.1038/s41443-020-00351-1

28. Tan WP, Levine LA. What can we do for chronic scrotal content pain? World J Mens Health. 2017;35(3):146-155. doi:10.5534/ wjmh. 17047

29. Oh PJ, Bajic P, Lundy SD, Ziegelmann M, Levine LA. Chronic scrotal content pain: a review of the literature and management schemes. Curr Urol Rep. 2021;22(2):12. doi:10.1007/s11934-02001026-6.

\section{Publish your work in this journal}

Research and Reports in Urology is an international, peer-reviewed, open access journal publishing original research, reports, editorials, reviews and commentaries on all aspects of adult and pediatric urology in the clinic and laboratory including the following topics: Pathology, pathophysiology of urological disease; Investigation and treatment of urological disease; Pharmacology of drugs used for the treatment of urological disease. The manuscript management system is completely online and includes a very quick and fair peer-review system, which is all easy to use. Visit http://www.dovepress.com/ testimonials.php to read real quotes from published authors. 